\title{
Linear 3-Hydroxybutyrate Tetramer (HB4) Produced by Sphingomonas sp. Is Characterized as a Growth Promoting Factor for Some Rhizomicrofloral Composers
}

\author{
Noriko Ogita, ${ }^{1}$ Yasuyuki Hashidoko, ${ }^{1, \dagger}$ Suwido H. Limin, ${ }^{2}$ and Satoshi Tahara ${ }^{1}$ \\ ${ }^{1}$ Division of Applied Bioscience, Graduate School of Agriculture, Hokkaido University, \\ Kita-ku, Sapporo 060-8589, Japan \\ ${ }^{2}$ Faculty of Agriculture, Palangkaraya University, Palangkaraya, Central Kalimantan, Indonesia
}

Received May 30, 2006; Accepted July 6, 2006; Online Publication, September 7, 2006

[doi:10.1271/bbb.60299]

\begin{abstract}
Sphingomonas spp. of $\alpha$-proteobacteria often play a role in assisting the development of microfloral communities under adverse soil conditions. Using a Frateuria sp. as an indicator for bacterial growth assay, we investigated the bacterial growth-promoting factor in the culture fluids of Sphingomonas sp. EC-K085. This factor was successfully isolated and identified as linear $(R, R, R, R)$-3-hydroxybutyrate tetramer (HB4), having a hydroxy-end and a carboxy-end group. When $28 \mu \mathrm{g}$ of HB4 was charged on a paper disc, impregnated Frateuria sp. cells in modified Winogradsky agar medium exhibited a promoted cell growth to form a clear colony emerging zone after a 2-day incubation.
\end{abstract}

Key words: bacterial cell growth-promoting factor; Frateuria sp.; linear 3-hydroxybutyrate tetramer; rhizobacteria; Sphingomonas sp.

Xyris complanata is a representative acid-tolerant, perennial herbal plant (Hashidoko et al., in submission). We have been interested in its adverse soil-adapting strategy and the ecological role of rhizospherous microorganisms inhabiting the rhizosphere and rhizoplane of $X$. complanata grown on acidic tropical peat soils. As a means to address this research goal, we have isolated more than 100 strains of bacteria from the rhizosphere and rhizoplane of $X$. complanata grown in several environmental conditions, under modified Winogradsky's (MW, adding $1 \%$ saccharose and $0.005 \%$ yeast extract) mineral solution-base solid plates that we often use for screening of oligotrophs and heterotrophs in the plant rhizosphere. ${ }^{1)}$ We found subsequently that acidtolerant and oligotrophic Sphingomonas spp. ${ }^{2)}$ and acidsusceptible and auxotrophic Frateuria spp. ${ }^{3)}$ (Fig. 1) are characteristic rhizobacterial groups in the rhizosphere and the rhizoplane respectively.

Due to compartmentalization in their habitat, we investigated the relationship between these Sphingomonas spp. and Frateuria spp. as to whether they affect each other in respect to their cell growth. Some Sphingomonas spp. displayed helper-like behaviors for a Frateuria sp. (Fig. 2A), similarly to observations in some Sphingomonas spp. towards other proteobacteria and/or fungi. ${ }^{4,5)}$ Generally, it is believed that bacteria are under severe competition in a nutrient-poor medium to acquire essential elements and energy sources to facilitate their survival. It is hence worth studying hypothetical biosignaling compounds produced by such Sphingomonas spp. that function to promote cell growth of auxotrophic Frateuria spp. in nutrient-poor media.

Sphingomonas sp. EC-K085 was cultured in modified Winogradsky's medium supplemented with $0.1 \% \mathrm{KNO}_{3}$ $\left(\mathrm{w} / \mathrm{v}\right.$ ) at $25^{\circ} \mathrm{C}$ at $80 \mathrm{rpm}$ (rotary-shaking) for $7 \mathrm{~d}$, and metabolites in the culture fluid $(14,500 \mathrm{ml})$, from which the cultured bacterial cells had been removed by centrifugation $(10,000 \times g$ for $15 \mathrm{~min})$, were subsequently trapped with a $\mathrm{C}_{18}$-coated silica gel (Cosmosil $75 \mathrm{C}_{18}$ PREP, Nacalai Tesque, Kyoto, Japan). The column was eluted with $\mathrm{MeOH}$, and eventually $640 \mathrm{mg}$ of crude extracts were obtained from 14.5-liter of the culture fluid. The crude extracts were re-dissolved in $36.25 \mathrm{ml}$ of $\mathrm{MeOH}$ (400 fold of the culture fluid) and subjected to a preliminary growth-promotion assay. Onto a paper disc, $50 \mu \mathrm{l}$ of the extract solution (equivalent to $20 \mathrm{ml}$ of the culture fluid) was charged, and the resulting disc was dried in vacuum to remove the solvent, and placed on a test bacterium-impregnated agar medium. The plate was incubated at $28{ }^{\circ} \mathrm{C}$ in the dark for $2 \mathrm{~d}$. Growthpromoting activity toward the impregnated Frateuria sp. EC-K130 was observed in the crude extract, as shown in Fig. $2 \mathrm{~B}$.

To chase the active principles, a large portion of $\mathrm{MeOH}$ eluates $(620 \mathrm{mg})$ was concentrated and redissolved in a small volume (about $1 \mathrm{ml}$ ) of $\mathrm{MeOH}$.

\footnotetext{
$\dagger$ To whom correspondence should be addressed. Fax: +81-11-706-4182; E-mail: yasu-h@abs.agr.hokudai.ac.jp

Abbreviations: HB4, 3-hydroxybutyrate tetramer; PHB, poly-3-hydroxybutyrate; MW, modified Winogradsky
} 


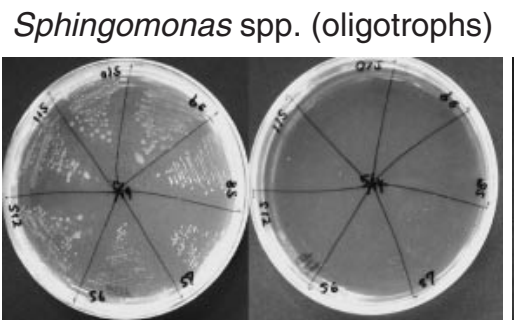

Winogradsky

Nutrient Broth

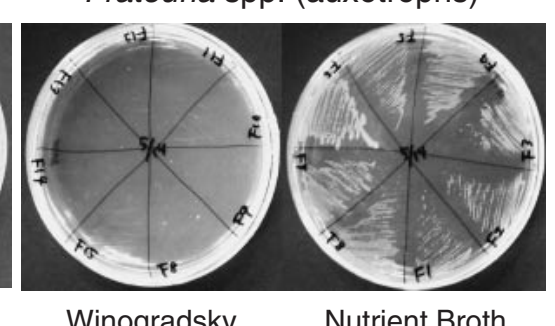

Fig. 1. Responses of Sphingomonas spp. and Frateuria spp. to Nutrient-Poor or Nutrient-Rich Medium.

Sphingomonas spp. and Frateuria spp., both isolated from several sites of Xyris complanata, were tested their growth performance on modified Winogradsky's medium (for oligotrophs) and nutrient broth medium (for auxotrophs). The agar plates (1.5\% agar), on which these bacterial strains had previously been inoculated, were incubated at $28^{\circ} \mathrm{C}$ for $2 \mathrm{~d}$ in the dark.

A

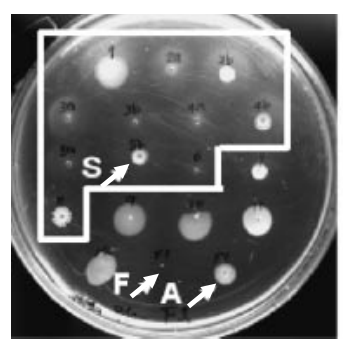

B

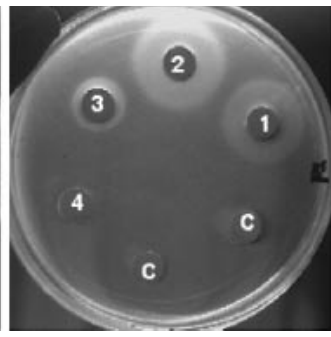

C

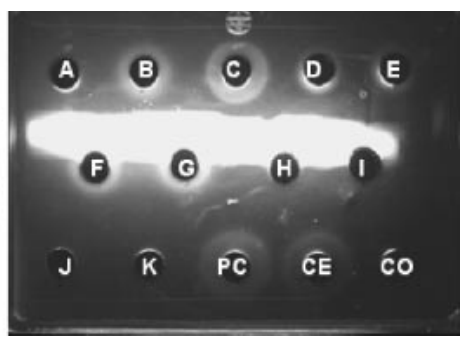

Fig. 2. Cell Growth-Promoting Effect of Sphingomonas sp. EC-K085 on Frateuria sp. EC-K130 Impregnated in MW Agar Medium.

All of the plates, having been impregnated with the Frateuria sp. EC-K130 as described in "Materials and Methods," were incubated at $28{ }^{\circ} \mathrm{C}$ in the dark for $2 \mathrm{~d}$. A, Not only Sphingomonas sp. EC-K085 (arrow, S) but also a further 15 sphingomonads isolated from X. complanata rhizosphere or the peat soil there were tested. Several isolates showed clear growth stimulation activities toward Frateuria sp. EC-K130 around the colonies of active sphingomonads (framed with a white line). Although some areas of growth promotion are ambiguous in the photo, the activity of these positive strains was obvious in megascopic observation. Frateuria sp. EC-K130 (arrow, F) and an isolate of Azospirillum sp. (arrow, A) were also inoculated as reference bacteria. Other bacteria without any arrow are inactive sphingomonads isolated from the same plant source. B, A cell growth-promoting principle was extracted with a Sep-Pak C18 cartridge ( $3 \mathrm{ml}$ of reverse-phase, Varian) in which $20 \mathrm{ml}$ of the bacterial culture fluid $\left(0.1 \% \mathrm{KNO}_{3}\right.$-supplemented $\mathrm{MW}$ liquid medium, incubated for $\left.7 \mathrm{~d}\right)$ had been passed. All of the MeOH eluates from the cartridge were concentrated and charged on a paper disc. The eluates also showed clear growth-stimulation activity toward impregnated ECK130. Nos. 1-3 are culture extracts of Sphingomonas spp., strains EC-K088, EC-K085, and EC-K129 respectively, while no. 4 is a culture fluid extract of Frateuria sp. EC-K130 prepared by the same process. C is a control (duplicated MeOH only). C, Among the fractions (A to K) obtained by the $\mathrm{C}_{18}$ reversed phase silica gel column chromatography as described, the most significant activity was apparent in fraction $\mathrm{C}$. PC and $\mathrm{CE}$ are positive controls (a volume-equivalent mixture of all fractions) and crude extract before column chromatography respectively, while $\mathrm{CO}$ is a control (MeOH only).

The dissolved eluates were then diluted 100 fold with $\mathrm{H}_{2} \mathrm{O}$ in preparation for placing them onto $80 \mathrm{~g}$ of Cosmosil $75 \mathrm{C}_{18}$-PREP column. We obtained 11 fractions by eluting the column with the following $\mathrm{MeOH}-$ water solvent system: $\mathrm{H}_{2} \mathrm{O}(100 \mathrm{ml} \times 2$, fractions $\mathrm{A}$ and B), $25 \% \mathrm{MeOH} / \mathrm{H}_{2} \mathrm{O}(100 \mathrm{ml} \times 3, \mathrm{C}, \mathrm{D}$ and $\mathrm{E}), 40 \%$ $\mathrm{MeOH} / \mathrm{H}_{2} \mathrm{O}(100 \mathrm{ml} \times 2, \mathrm{~F}$ and $\mathrm{G}), 60 \% \mathrm{MeOH} / \mathrm{H}_{2} \mathrm{O}$ $(100 \mathrm{ml} \times 2, \mathrm{H}$ and $\mathrm{I}), 80 \% \mathrm{MeOH} / \mathrm{H}_{2} \mathrm{O}(200 \mathrm{ml}, \mathrm{J})$ and $100 \% \mathrm{MeOH}(200 \mathrm{ml}, \mathrm{K})$. All of the fractions obtained were dried in vacuum, and the resulting eluates were then re-dissolved in a constant-volume of $1.40 \mathrm{ml}$ of $\mathrm{MeOH}$ (each 10,000 fold of the culture fluid). Ten-times diluted extract solution $(50 \mu \mathrm{l}$, equivalent to $50 \mathrm{ml})$ was each charged to a paper disc. The resulting discs were assayed by the same process as described for the crude extract.

Some fractions (B, C, D, E, F, and G) had growthpromoting activities toward EC-K130 (Fig. 2C). The activity of fraction $\mathrm{C}(30.2 \mathrm{mg})$ was much clearer than those of other fractions exhibiting an ambiguous growth zone, so that a portion of fraction $\mathrm{C}(6.4 \mathrm{mg}$, obtainable from $3,000 \mathrm{ml}$ of culture fluid) was further fractionated by preparative TLC (in $\mathrm{MeOH}-\mathrm{H}_{2} \mathrm{O}$ 2:1) on reversephase silica gel plate (RP-18 $\mathrm{F}_{254 \mathrm{~S}} 15389$, Merck, Darmstadt, Germany) in guidance with detection under UV $365 \mathrm{~nm}$ and $254 \mathrm{~nm}$ lights. Only one quenching spot at $R_{\mathrm{f}}$ 0.56-0.62 (fraction C-1) showed activity.

The active fraction $\mathrm{C}-1$ thus obtained was further subjected to a purification process using reversed phase HPLC in $\mathrm{MeOH}-\mathrm{H}_{2} \mathrm{O}$ 2:1, setting an UV detector at $284 \mathrm{~nm}$ due to maximal UV absorption of fraction C-1. Accordingly, active substance possessing no conjugation system in the molecule was eluted $\left(t_{\mathrm{R}} 4.0-5.9 \mathrm{~min}\right)$ in front of the main UV peak ( $t_{\mathrm{R}} 7.0 \mathrm{~min}$ ), which was identified as 4-hydroxybenzencarbaldehyde (spectral data not shown). The purified chemical substance 


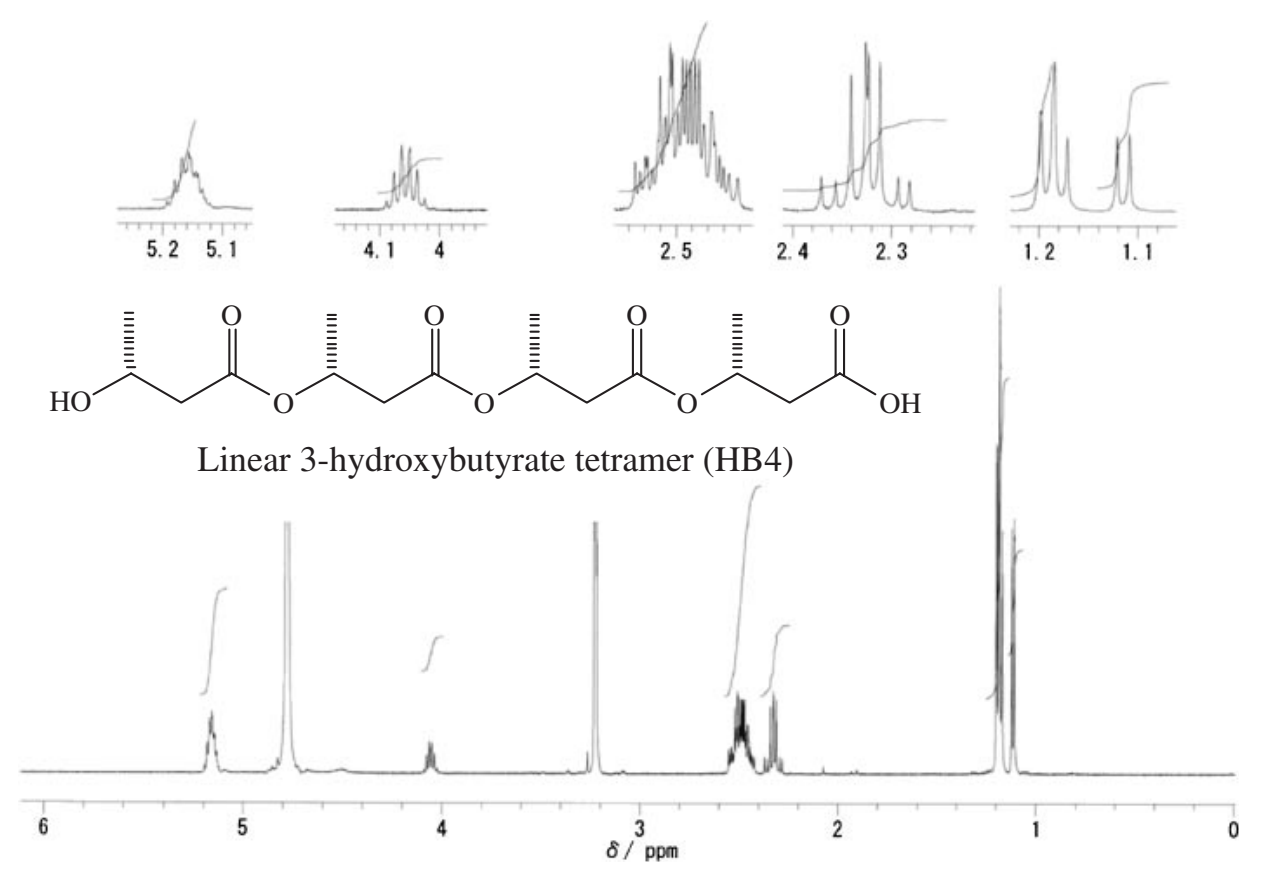

Fig. 3. ${ }^{1} \mathrm{H}-\mathrm{NMR}$ Spectrum $\left(\mathrm{CD}_{3} \mathrm{OD}\right)$ and Chemical Structure of Active Principle (HB4) Purified from Fraction C-1.

$(1.7 \mathrm{mg})$ showed a growth-promoting activity nearly equivalent to the crude fraction $\mathrm{C}$.

The purified active principle gave a parent ion at $m / z$ $363\left(\mathrm{M}^{+}+\mathrm{H}, 100 \%\right)$ in FD-MS. In EI-MS, its fragmentation indicated a repeated fission losing 86 mass units. By negative FAB-HR-MS analysis, the molecular formula $\left([\mathrm{M}-\mathrm{H}]^{-}\right)$was confirmed to be $\mathrm{C}_{16} \mathrm{H}_{25} \mathrm{O}_{9}$ (found 361.1505, calcd. 361.1499). ${ }^{1} \mathrm{H}-\mathrm{NMR}$ spectrum together with ${ }^{1} \mathrm{H}-{ }^{1} \mathrm{H}-\mathrm{COSY},{ }^{13} \mathrm{C}-\mathrm{NMR}$, DEPT, HMQC, and $\mathrm{HMBC}$ in $\mathrm{CD}_{3} \mathrm{OD}$ showed the presence of four methyl $\left(\delta_{\mathrm{H}} 1.11,1.18,1.19\right.$, and 1.19$)$, four methine $\left(\delta_{\mathrm{H}}\right.$ 4.05 and at $\delta_{\mathrm{H}} 5.12-5.19$ for $3 \mathrm{H}$ ), and four pairs of methylene $\left(\delta_{\mathrm{H}} 2.31\right.$ and 2.35 , and three sets at $\delta_{\mathrm{H}} 2.41-$ 2.56 for $6 \mathrm{H}$ ) proton signals. The methyl signals (all doublets, $J=6 \mathrm{~Hz}$ ) were coupled with the oxygenated methine signals, and the set of methine signals was further coupled with the methylene signals. A set of proton-coupling sequences in those showing upfieldshifts at $\delta_{\mathrm{H}} 1.11\left(\mathrm{CH}_{3}\right), 4.05(\mathrm{CH})$, and $\delta_{\mathrm{H}} 2.31$ and 2.35 $\left(-\mathrm{CH}_{2}\right)$ was reasonably assignable to the hydroxy-end 3hydroxybutyrate moiety of this compound (Fig. 3). Accordingly, the active principle was found to be a linear-type 3-hydroxybutyrate tetramer (HB4), of which ${ }^{1} \mathrm{H}$ - and ${ }^{13} \mathrm{C}$-NMR chemical shifts were found to be in good accordance with those of authentic $(R, R, R, R)-\mathrm{HB} 4$, as previously reported by Bachmann and Seebach.6)

Poly-3-hydroxybutyrate (PHB, also a synonym of $\beta$-hydroxybutyrate polymer or 3-hydroxybutyrate polymer) is one of the most representative bacterial polymeric substances for several free-living nitrogen-fixing bacteria. Poly-3-hydroxybutyrate depolymerase (PHBDP), which catalyzes endo-type hydrolysis of PHB to produce several linear-type 3-hydroxybutyrate oligomers, including HB4, is also produced by many soil bacteria. ${ }^{7,8)}$ Sang has reported that the absolute configuration of 3-hydroxybutyric acid and the 3-hydroxybutyrate unit of PHB produced by proteobacteria is generally in the $R$-configuration. ${ }^{9)}$ Bachmann and Seebach have also reported optical rotation of synthesized $(R, R, R, R)-\mathrm{HB} 4$ as $[\alpha]_{\mathrm{D}}-16^{\circ}(c=1.0$ in $\left.\mathrm{MeOH}),{ }^{6}\right)$ and the HB4 we have isolated showed a levorotatory $\left([\alpha]_{\mathrm{D}}-12^{\circ}, c=0.65\right.$ in $\left.\mathrm{MeOH}\right)$. Considering these features together, it is concluded that all of the four chiral carbons of HB4 produced by EC-K085 are in the $R$-configuration.

Since saccharose is contained in MW medium at $1 \%$ concentration, it is obvious that the effective role of HB4 is not a simple carbon source. Instead, it is most likely playing a role as a certain functional principle. Because PHB is known to be a chelating agent towards several metal cations by capturing them inside the helix of its chain, ${ }^{10,11)}$ it may function as metal cation ionophores. In fact, in not a few cases, cell growth of a hardly culturable microorganism is regulated by only one limiting nutritional factor. Hoo et al. reported that $\mathrm{Mg}^{2+}$ was the limiting factor for the cell growth of Sphingobium yanoikuyae EC-S001, which is difficult to culture in commercial potato-dextrose broth (Difico, Boston, MA). ${ }^{12)}$ In this case, the threshold level of $\mathrm{Mg}^{2+}$ for normal growth of strain EC-S001 is $0.10 \mathrm{~mm}$, but the standard potato-dextrose broth medium contained only $0.05 \mathrm{~mm}$ of $\mathrm{Mg}^{2+}$. Similarly to this example, HB4 may assist effective assimilation of certain cations or other nutrient serving as a limiting factor for the cell growth of auxotrophic Frateuria sp. in nutrient-poor media. It is necessary to confirm whether HB4 is applicable in artificial media to enhance the growth of ceratin hardly culturable bacteria. 
At the present time, the physiology and ecological roles of PHB in polymer-producing bacteria is not well understood. Some studies using bacterial mutants which lacked the ability to produce PHB showed that PHB suppresses bacterial metabolisms and also extends bacterial life-spans in bulk soil. ${ }^{13)}$ In our study, HB4 produced by Sphingomonas sp. EC-K085 was characterized as a candidate for an important chemical signal among rhizospherous microbial communities that functions to increase their microfloral diversity. As a related phenomenon, Tanaka et al. reported that a Sphingomonas sp. in activated sludge enabled an unculturable Catellibacterium nectariphilum to become culturable, contributing to microfloral development in the sludge. ${ }^{5)}$ Despite efforts at isolation and characterization of the growth promoting chemical factor produced by the Sphingomonas sp., it is not yet characterized completely.

Some other acidic soil tolerant rhizobacteria (e.g., Burkholderia spp.) also showed similar growth-promoting effects on impregnated slow-growing rhizobacteria (e.g., another Burkholderia sp. and a Pantoea sp. isolated from Melastoma malabathricum and Artocarpus champeden). It is thus most likely that HB4 is the major growth-promoting principle, and chemical investigation of them may reveal a complicated regulation system of unculturable microfloral communities. Further ecochemical and biochemical studies of 3-hydroxybutyrate oligomers are currently in progress, and their details will be reported elsewhere as a full paper.

The materials and methods part in this communication is as follows.

General: EI-MS and FD-MS were measured by JEOL JMS-01SG-2 and JEOL JMS-DX300 (Tokyo) respectively. ${ }^{1} \mathrm{H}$ - and ${ }^{13} \mathrm{C}-\mathrm{NMR}$ data were assigned by $2 \mathrm{D}$ NMR experiments (HH-COSY, HMBC and HMQC) by using a Bruker AMX500 $\left({ }^{1} \mathrm{H}\right.$ : $500 \mathrm{MHz}$ and ${ }^{13} \mathrm{C}$ : $125 \mathrm{MHz}$ ). The optical rotation value was measured in $\mathrm{MeOH}$ with a JASCO DIP-370 Digital Polarimeter, using a quartz cell $(\phi 3.5 \mathrm{~mm} \times 10 \mathrm{~mm}$ thick $)$. Final purification of the active principle was done by HPLC (a Hitachi L-6000 equipped with a Hitachi L-4200H UV-VIS detector) connected with a reverse phase column (YMC-Pac PolymerC18, $\phi 4.6 \mathrm{~mm} \times 250 \mathrm{~mm}$ long). $\mathrm{MeOH}-\mathrm{H}_{2} \mathrm{O}$ 2:1 was used as an isocratic solvent with a UV detector set at $284 \mathrm{~nm}$ to yield two chemical substances.

Isolation and identification of bacteria. X. complana$t a$, used as a bacterial source, was a specimen forming a pure community in a topsoil-removed peatland near Palangkaraya, Central Kalimantan, Indonesia. The root of the plant was first washed well with clean water in a handy spray bottle, and the resulting roots were cut into several fragments $(2-3 \mathrm{~cm})$ and transferred into a $50 \mathrm{ml}-$ Falcon tube, in which $30 \mathrm{ml}$ of sterilized water was filled. The Falcon tube was then shaken for $5 \mathrm{~s}$, and the root fragment was inoculated into $\mathrm{N}$-free gellan gum medium to trap rhizoplane bacteria. The remaining root washings in the Falcon tube were directly used as an inoculant to search for rhizospherous bacteria on MW agar plates. Bacterial identification was done based on 16S rRNA gene sequence determination and a homology search on GeneBank database. Sphingomonas sp. ECK085 (accession no. AB264174) and Frateuria sp. ECK130 (AB264175) were isolated from the rhizosphere and rhizoplane of the host plant respectively.

Bioassay: We performed a paper disc assay $(8 \mathrm{~mm}$ diameter with $2 \mathrm{~mm}$ thickness, Advantec, Tokyo) in the search for growth-promoting factors in the culture fluid of Sphingomonas sp. MW solution adjusted to a final $\mathrm{pH}$ of 6.0 with a small volume of $4 \mathrm{M} \mathrm{H}_{2} \mathrm{SO}_{4}$ was added to $0.5 \%$ agar and then autoclaved at $120^{\circ} \mathrm{C}$ for $30 \mathrm{~min}$. Cooling below $45^{\circ} \mathrm{C}$, a cell suspension of Frateuria sp. EC-K130 (OD 0.1 or more) precultured on an MW agar plate for $2-3 \mathrm{~d}$ ( $1 \mathrm{ml}, 10^{7}$ cells) was added and vortexed well to cast onto agar plates $(9 \mathrm{~cm}$ diameter, $15 \mathrm{ml}$ of gel volume).

Physicochemical properties of linear (R,R,R, R)-3hydroxybutyrate tetramer (HB4): colorless syrup; FDMS ( $m / z$, rel. int. \%): $363\left(\mathbf{M}^{+}+\mathrm{H}, 100\right)$; EI-MS $(m / z$, rel. int. \%): 277 (15), 259 (13), 214 (17), 191 (25), 173 (63), 155 (95), 128 (27), 105 (20), 87 (61), 69 (100), and 43 (23); FAB-HR-MS (negative mode): $\mathrm{C}_{16} \mathrm{H}_{25} \mathrm{O}_{9}$ (found 361.1505, calcd. 361.1499); $[\alpha]_{\mathrm{D}}-12^{\circ}(c=$ 0.65 in $\mathrm{MeOH}) ;{ }^{1} \mathrm{H}-\mathrm{NMR}\left(\delta_{\mathrm{H}}\right.$ in $\left.\mathrm{CD}_{3} \mathrm{OD}, 500 \mathrm{MHz}\right)$ : 5.12-5.19 (3H, m), $4.05(1 \mathrm{H}, \mathrm{m}), 2.41-2.56(6 \mathrm{H}, \mathrm{m})$, $2.35(1 \mathrm{H}, \mathrm{dd}, J=15$ and $7 \mathrm{~Hz}), 2.31(1 \mathrm{H}, \mathrm{dd}, J=15$ and $5 \mathrm{~Hz}), 1.19(6 \mathrm{H}, \mathrm{d} \times 2, J=6 \mathrm{~Hz}), 1.18(3 \mathrm{H}, \mathrm{d}, J=$ $7 \mathrm{~Hz})$, and $1.11(3 \mathrm{H}, \mathrm{d}, J=6 \mathrm{~Hz}) ;{ }^{13} \mathrm{C}-\mathrm{NMR}\left(\delta_{\mathrm{C}}\right.$ in $\left.\mathrm{CDCl}_{3}, 125 \mathrm{MHz}\right)$ : $172.3(\mathrm{CO}), 169.5(\mathrm{CO} \times 2), 169.4$ (CO), $68.0(\mathrm{CH}), 68.0(\mathrm{CH}), 67.9(\mathrm{CH}), 64.7(\mathrm{CH}), 43.5$ $\left(\mathrm{CH}_{2}\right), 41.0\left(\mathrm{CH}_{2} \times 2\right), 40.7\left(\mathrm{CH}_{2}\right), 22.4\left(\mathrm{CH}_{3}\right), 20.1$ $\left(\mathrm{CH}_{3}\right), 20.0\left(\mathrm{CH}_{3}\right)$, and $19.9\left(\mathrm{CH}_{3}\right)$.

\section{Acknowledgments}

The authors thank Mr. K. Watanabe and Dr. E. Fukushi (MS and NMR Laboratory, Graduate School of Agriculture, Hokkaido University) for MS and NMR measurements, and also gratefully acknowledge Professor C. Hanny Wijaya (Department of Food Science, Bogor Agricultural University) and Professor Mitsuru Osaki (Graduate School of Agriculture, Hokkaido University) for the arrangements for our research trip to Central Kalimantan. This research was supported by the JSPS (Japan Society for the Promotion of Science) Core University Program between LIPI (the Indonesian Institute of Science)-Hokkaido University, and also by Grant-in-Aids for Scientific Research from JSPS (no. 13575031 and 16208032 to Y.H.).

\section{References}

1) Hashidoko, Y., Tada, M., Osaki, M., and Tahara, S., Soft gel medium solidified with gellan gum for preliminary screening for root-associating, free-living nitrogen-fixing bacteria inhabiting the rhizoplane of plants. Biosci. 
Biotechnol. Biochem., 66, 2259-2263 (2002).

2) Yabuuchi, E., Yano, I., Oyaizu, H., Hashimoto, Y., Ezaki, T., and Yamamoto, H., Proposals of Shingomonas paucimobilis gen. nov. and comb. nov., Sphingomonas parapaucimobilis sp. nov., Sphingomonas yanoikuyae sp. nov., Sphingomonas adhaesiva sp. nov., Sphingomonas capsulata comb. nov., and two genospecies of the genus Sphingomonas. Microbiol. Immunol., 34, 99-119 (1990).

3) Swings, J., Gillis, M., Kersters, K., Devos, P., Gossele, F., and Deley, J., Frateuria, a new genus for "Acetobacter aurantius." Int. J. Syst. Bacteriol., 30, 547-556 (1980).

4) Hashidoko, Y., Ecochemical studies of interrelationships between epiphytic bacteria and host plants via secondary metabolites. Biosci. Biotechnol. Biochem., 69, 14271441 (2005).

5) Tanaka, Y., Hanada, S., Manome, A., Tsuchida, T., Kurane, R., Nakamura, K., and Kamagata, Y., Catellibacterium nectariphilum gen. nov., sp. nov., which requires a diffusible compound from a strain related to the genus Sphingomonas for vigorous growth. Int. J. Syst. Evol. Microbiol., 54, 955-959 (2004).

6) Bachmann, B. M., and Seebach, D., Synthesis and structure of linear and cyclic oligomers of 3-hydroxybutanoic acid with specific sequences of $(R)$ - and $(S)$ configurations. Helv. Chim. Acta, 81, 2430-2461 (1998).
7) Sugiyama, A., Kobayashi, T., Shiraki, M., and Saito, T., Roles of poly(3-hydroxybutyrate) depolymerase and 3HB-oligomer hydrolase in bacteria PHB metabolism. Curr. Microbiol., 48, 424-427 (2004).

8) Scherer, T. M., Fuller, R. C., Goodwin, S., and Lenz, R. W., Enzymatic hydrolysis of oligomeric models of poly-3-hydroxybutyrate. Biomacromolecules, 1, 577583 (2000).

9) Sang, Y. L., Bacterial polyhydroxyalkanoates. Biotech. Bioengineer., 49, 1-14 (1996).

10) Pavlov, E., Grimbly, C., Diao, C. T. M., and French, R. J., A high-conductance mode of a poly-3-hydroxybutyrate/calcium/polyphosphate channel isolated from competent Escherichia coli cells. FEBS Lett., 579, 51875192 (2005).

11) Reusch, R., Biological complexes of poly-beta-hydroxybutyrate. FEMS Microbiol. Rev., 103, 119-129 (1992).

12) Hoo, H., Hashidoko, Y., Islam, M. T., and Tahara, S., Requirement of a relatively high threshold level of $\mathrm{Mg}^{2+}$ for cell growth of a rhizoplane bacterium, Sphingomonas yanoikuyae EC-S001. Appl. Environ. Microbiol., 70, 5214-5221 (2004).

13) Lopez, N. I., Ruiz, J. A., and Mendez, B. S., Survival of poly-3-hydroxybutyrate-producing bacteria in soil microcosms. World J. Microbiol. Biotech., 14, 681-684 (1998). 